\title{
연구논문
}

\author{
내륙습지 기능의 우선순위 결정 \\ 이승준 ${ }^{*} \cdot$ 최현아* · 이우균* · 이종렬* · 전성우** · 김준순*** \\ 고려대학교 환경생태공학과*, 한국환경정책 - 평가연구원 환경정보연구실**국립강원대학교 산림경영학과***
}

\section{Determining the priority order of wetland functions}

\author{
Seungjun Lee* $\cdot$ Hyun-Ah Choi* $\cdot$ Woo-Kyun Lee* \\ Jong Yeol Lee* . Seong Woo Jeon** · Joonsoon Kim***
}

Department of Environmental Science and Ecological Engineering, Korea University*

Division of Natural Resources Conservation, Korea Environment Institute**

Department of Forest Management, Kangwon National University***

\begin{abstract}
In this study, the functional priority of wetlands was determined through analysis of previous research. To determine relative importance, three processes were performed. First, quantitative values from the case studies were normalized. Second, non-quantitative values were prioritized based on standard criteria. Third, equal weight was applied as long as there was no special consideration regarding a particular value's disproportionate priority in the research. Finally, results were grouped into large, medium, and small classes.In this study, the functions of the medium class were found to be the most significant, in the following order of priority: water supply and ground water recharge; culture and recreation; biodiversity; product; water quality control; flood control; erosion control; moderation of climate change; and provision of biochemical matter. To verify these results, we compared our findings with those of an assessment that used the Rapid Assessment Method (RAM) on the same type of study area. Whereas this comparison indicated some correlations by the culture, water storage, and genetic sustainability functions, it suggested a lack of such relationship by the water purification and flood prevention functions.
\end{abstract}

Keywords : Wetland, Ecosystem functions, Impact Assessment, Evaluation

Corresponding Author: Woo-Kyun Lee, \#319, East Building, College of Life Science and Biotechnology, Korea University, 145 AnamRo, Seongbuk-Gu, Seoul, 136-713, Korea Tel: +82-2-3290-3016 Email: leewk@korea.ac.kr Received : 27 February, 2014. Revised : 23 May, 2014. Accepted : 27 May, 2014. 


\section{I. 서 론}

자연자산에 대한 가치평가는 인간에게 어떠한 효 용을 주는지와 인간에게 얼마나 유익한 기능을 하는 가에 대한 평가로부터 시작된다. 이는 인간이 느끼는 효용에 대한 평가이며, 그 자체가 자연자산에 대한 가치와 밀접하게 연결되어 있다. Costanza et al. (1997)의 연구 이후에 자연자산의 가치 평가에 관심 이 높아졌고, 2005년 새천년생태계평가(Millennium ecosystem Assessment, MA)가 이루어진 후에 국제 적으로 연구가 확산되기 시작하였다. $\mathrm{MA}(2005)$ 에서 는 자연자산이 인간에게 주는 효용을 4 가지 서비스 (Service)의 형태로 구분하였고, 이를 통해 자연자산 이 가지고 있는 가치를 평가하려고 시도하였다. 이러 한 노력 가운데, 국내 · 외 연구에서 자연자산에 대한 평가는 주로 산림, 습지, 초지를 중심으로 이루어지고 있다(구본학 - 김귀곤, 2001 ; 강수진, 2004 ; 김종호 등, 2006; 이상영, 2007; Brinson et al., 1995). 특히, 습지는 식량, 음용수 공급, 종 다양성 등 직접적인 기 능과 더불어 홍수의 방지, 토양 형성과 같은 간접적인 기능을 제공하며 인간과 밀접한 관계가 있기 때문에 중요하게 다뤄지고 있다(Barbier et al., 1997).

Hammitt et al.(2001)은 습지에 대한 보호가치를 지역주민을 대상으로 실시한 설문방식의 가상가치평 가법(Contingent Valuation method; CVM)을 이용 하여 지불의사액(Willingness To Pay; WTP)을 추 정하였다. 이와 같은 습지의 평가 방식은 Bateman et al.(1995)에 의해 그에 대한 연구방법의 고찰이 이루어졌다. 습지의 평가 방법 중 수문지형학적 (Hydrogeomorphic; HGM) 방법은 생태학, 생지화 학, 수문학적인 측면을 고려하여 평가하는 방법이다. Brinson et al.(1995)은 HGM 방법의 접근방식을 통 해 하천 습지의 평가 기준을 수문학, 생지화학, 식물 상, 동물상의 4 가지 항목으로 나누고, 각 분류의 기 능을 기준 습지와의 비교를 통해 상대적인 지표를 산출하는 방법론을 제안하였으며, Whigham(1999) 은 이 방식의 습지 평가 방법을 미국의 생태학 정책 학적인 관점에서 평가하였다. 일반적 수준의 습지기 능을 평가할 수 있는 간이기능평가의 대표적인 방법
인 일반기능평가방법(또는 신속평가방법, Rapid Assessment Method; RAM)은 미국의 습지관리 전 략수립을 위한 기초평가에 적용되고 있다. Tilton et al.(2001)은 Rouge River 습지에 대한 기능을 동식 물의 서식처 제공기능, 홍수저장기능, 유출감쇄기능, 수질보호기능, 수변보호기능, 미적기능으로 분류하 고 각 기능에 대해 RAM을 통해 평가하였다. Sutula et al.(2006)은 RAM을 지역의 특성에 맞게 계량화 시킨 캘리포니아 일반기능평가방법(California Rapid Assessment Method; CRAM)을 제안하기로 하였다. 이와 같은 습지평가에 대한 해외사례에서는 각 연구지역에 대한 개략적인 평가만 시행되어 왔으 며, 평가 시 유형이 고려되지 않은 연구가 많아 유형 별 변이가 큰 습지의 평가는 편차 또한 크게 나타나 므로 이를 극복하기 위해 유형을 고려한 평가가 필요 한 실정이다.

구본학 - 김귀곤(2001)은 8개의 습지 기능에 대해 서 RAM을 이용한 국내습지의 기능 평가를 실시하였 다. 강수진 (2004)은 Rapid Appraisal Wetland Condition Index(RAW)법 과 Index of Stream Condition(ISC)법을 이용한 우리나라 습지기능평가 를 위한 기준을 수립하였다. 신한규 등(2009)은 댐습 지를 $\mathrm{HGM}$ 방법으로 평가한 후에 댐습지에 대한 관 리방안을 제안하였으며, 이관규 등(2010)은 선행연 구 사례를 검토하여 RAM의 국내적용을 위해 평가 기준을 총 8 개의 평가항목과 총 48 개의 평가요소로 수정하여 제안하였다.

그러나 국내의 습지에 관한 평가사례는 CVM과 같 은 설문조사와 등급화 평가(RAM, HGM) 방식에 그 치고 있으며, 정량적 평가를 위한 객관적 타당성과 이를 뒷받침할 수 있는 근거가 상대적으로 미흡하다. 또한, 습지의 경우 산림이나 초지에 비해 그 공간적 범위를 구체적으로 구획하기 힘들기 때문에, 정량적 평가를 하기가 어려운 실정이다.

선행연구의 검토결과, 습지의 기능에 대한 다양한 평가 방법이 존재하지만, 이를 우리나라에 직접 적용 하기에는 한계가 있으며, 습지 기능에 대한 평가 시 우선순위에 대한 선정이 없이 진행됨에 따라 중요하 지 않은 기능이 평가되는 경우가 발생하고 있다고 판 
단된다. 이렇게 습지에 대한 모든 기능을 평가할 수 없기 때문에, 기능에 대한 평가가 이루어지기 전에 우선순위에 대한 고려가 반드시 필요하다고 볼 수 있 다. 따라서, 본 연구에서는 다양한 국내외 연구를 검 토하여 습지의 기능을 분류하고, 중요도에 근거한 우 선순위를 도출하였다. 평가된 우선순위는 유형별로 구분하여 기존 습지평가방법인 RAM 을 통해 그 타 당성을 간접적으로 검증하고자 하였다.

\section{II. 재료 및 방법}

\section{1. 연구재료}

습지에 대한 평가는 정성적인 평가 방법인 CVM 평가 방식과 1990년대에 국외에서 개발된 RAM 평 가 방법이나 HGM기법을 이용하여 시행되어 왔다 (Tilton et al., 2001). RAM 평가방법은 일반적으로 습지를 평가하는데 쓰이는 대표적인 방법으로써 이 를 이용한 국내 습지연구가 진행되어 왔으며(구본 학 - 김귀곤, 2001), 또 다른 방법인 HGM 평가기법 은 습지의 수문학, 생지화학, 동식물상을 평가하는 방법이다(Whigham, 1999). 이러한 사전연구결과의 검토를 통해 우선순위 결정하는 자료로 활용하였다. 우선순위 결정에 사용된 국내외 대표적인 연구는 구 본학과 김귀곤 (2001), 강만옥 등(2008), 윤선하(2009), 김형수 등(2009), Brinson et al.(1995), Barbier et al.(1997), Constanza et al.(1997), Brouweret al (1999), Robert et al.(1998), Woodward et al.(2001), de Groot et al.(2002), Ghermandi et al.(2008), Teracino et al.(2012) 등 이며, 검토된 습지기능은 중분류 10 개에 해당하는 총 41 개 세분류 기능에 대하 여 우선순위를 평가하였다. 평가된 사례 중 등급화 방 법을 통해 습지를 평가한 사례는 국외의 경우 Brinson et al.(1995), Brouwer et al.(1999), Woodward and Wui(2001), de Groot et al.(2002)등이 있으며, Barbier et al.(1997), Costanza et al.(1997)와 Ghermandi et al.(2008)는 습지기능의 경제적 가치를 평가하였 다. 국내연구 중 강만옥(2008)은 경제적 가치평가관 련 연구를 진행하였으며, 구본학 - 김귀곤(2001), 김
형수 등(2009), 윤선하(2009)의 연구에서는 등급화 를 통한 기능평가가 시도되었다.

\section{2. 연구 방법}

본 연구에서는 Figure 1과 같이 기존의 습지 분류 및 기능 연구 사례를 통해 습지의 유형별 기능을 구 분하고, 평가된 기능에 가중치를 부여하여 우선순위 를 결정하였다. 이와 같이 결정된 우서순위를 RAM 결과와 비교하여 활용성을 검증하였다.

\section{(1) 우선순위 결정}

\section{1) 습지유형별 기능 구분}

우선순위 결정을 위한 국내외 대표적 논문을 통해 서 습지의 Ramsar 유형 및 기능을 구분하고 행렬표 로 구성하였다. 습지에 대한 기능은 세분류, 중분류 를 먼저 구분하고, 대분류의 경우는 세 - 중분류 결과 를, $\mathrm{MA}(2005)$ 기준에 따라서 별도로 군집화하는 방 법으로 구분하였다. 기존 연구를 검토하여 실제로 기 능에 대한 평가가 이루어진 사례에 대해서 정리하였 으며, 이 사례 외에도 기능에 대한 구분만 연구된 사

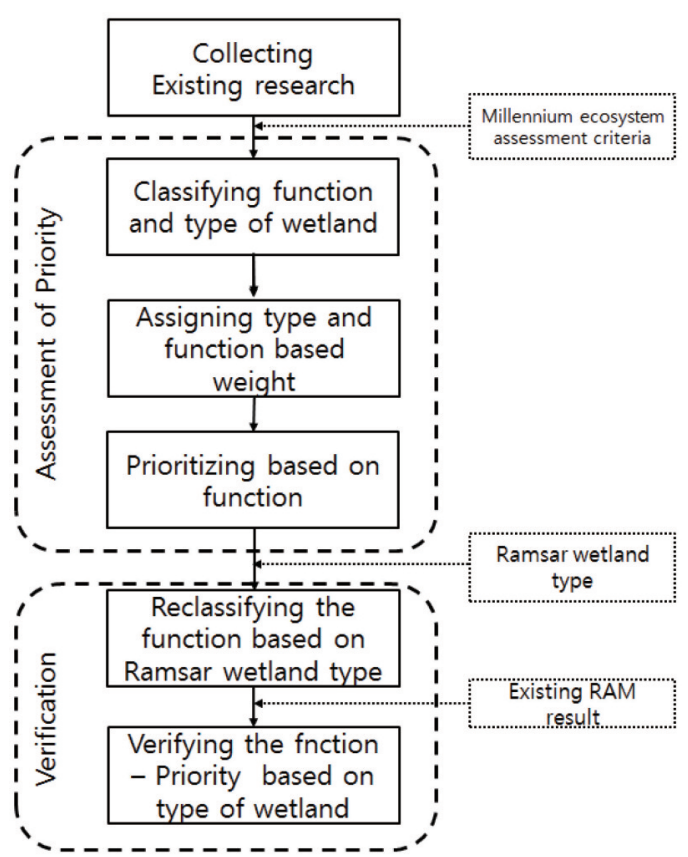

Figure 1. Method for wetland priority assessment and verification 
Table 1. Criteria of standardization and assigning weight method on wetland function assessment result

\begin{tabular}{|c|c|c|c|c|}
\hline \multirow{2}{*}{ Assessment } & \multirow{2}{*}{ Standardization } & \multicolumn{3}{|c|}{ Weight } \\
\hline & & 1 & 2 & 3 \\
\hline Economic & $N=\frac{\alpha-\min }{\max -\min }$ & $\mathrm{N} \leqq 0.3$ & $0.3<\mathrm{N} \leqq 0.6$ & $0.6<\mathrm{N}$ \\
\hline Rating & - & Minimum Value & Medium & Maximum Value \\
\hline None & \multicolumn{4}{|c|}{ Identifying $\left({ }^{*}\right)$} \\
\hline
\end{tabular}

례들도 포함하였다. 각 평가 방법에 따라 아래 Table 1 의 표준화 방법에 따라서 점수화 하였고, 이를 합산 하여 우선순위가 평가될 수 있도록 하였다.

\section{2) 습지 유형 및 기능별 가중치 부여}

기존의 사례들을 검토하여, 습지의 각 기능에 대한 평가결과를 기초로 우선순위를 결정하였다. 첫째, 습 지 기능의 정도를 구분할 때 그 그분이 애매하고 정 확하기 평가하기 어렵기 때문에 경제적 가치로 평가 된 사례에서는 각 기능별로 평가된 금전적 가치를 표 준화하여 0 부터 1 사이의 값으로 나타내었다. 이때 0 과 1사이 구간 내에서는 일정한 값을 가질 수 있다는 가정을 바탕으로 표준화된 값을 $0 \sim 0.3$ 은 $1,0.3 \sim$ 0.6 사이의 값은 2 를 부여하고 나머지에 대해서는 3 의 가중치를 부여하였다(Table 1).

둘째, 등급으로 평가된 사례는 RAM 습지 기능분 류에 따라 3 단계(상, 중, 하) 혹은 등급의 개수대로 평가 결과를 부여하였으며, 가장 낮은 등급에 대한 점수는 1 , 높은 등급에 대한 점수는 3 의 가중치를 부 여하며 나머지에 대해서는 2 를 부여하였다.

마지막으로 습지의 기능 분류를 소개한 연구는 기 능간의 차별성을 두지 않은 결과이기 때문에, 이런 형태의 연구에 대해서는 각 기능에 가중치를 동일하 게 적용하였다.

\section{3) 기능별 가중치 합산 우선순위 결정}

각 기능별로 부여된 가중치를 세분류, 중분류, 대 분류 별로 합산하여 우선순위를 결정하였다. 결정된 우선순위는 표로 정리하여, 각 분류별로 어떠한 기능 의 우선순위가 높게 평가되었는지 분석하였다.

\section{(2) 비교검증}

현재 국내 · 외의 다양한 연구에서 MA(2005)를 기
초로 한 자연자산의 가치평가가 진행되고 있는데, 이 러한 과정에서 모든 항목을 다 평가할 수 없기 때문 에, 생태계 기능에 대한 우선순위를 결정하는 것은 반드시 필요하다. 본 연구에서 우선순위에 대한 우리 나라의 적용가능성을 위해 우리나라 내륙습지 RAM 결과(전우송 등, 2007)와 비교를 하였다. 기존 평가 방법과 비교를 위해서는 그 기준을 일치시키는 것이 중요하다. 이를 위해서, 본 연구에서는 람사르의 하 천형 습지 유형으로 도출된 우선순위 결과를 RAM에 의해 조사된 결과와 비교하였다.

\section{III. 결과 및 고찰}

\section{1. 습지기능 군집 및 우선순위}

\section{(1) 습지 유형 및 기능의 표준화된 가중치}

Table 2는 1971년 람사르 회의를 통해 채택되었으 며 현재 국내 습지 인벤토리 작성에 활용되고 있는 람사르 유형에 따른 습지유형(세로축) 및 기능(가로 축) 행렬에 부여한 가중치를 나타낸다. 이 가중치에 서, 내륙습지의 하천형, 소택형, 그리고 호수형에 대 한 기능 가중치를 합산하여 각 중분류 유형에 대한 기능 가중치를 비교해보았다. 또한 세분류의 기능별 가중치는 기능(가로축)의 중분류, 대분류 수준으로 합산하여 습지 기능의 중요도를 비교하는데 활용하 였다. 환경부(2011) 분류체계의 경우 수문과 지형학 적 특징만을 반영하고 있으나, 람사르 습지 유형은 1971년 이란에서 열린 국제회의 시 채택한 습지 유형 구분 체계(Ramsar, 1971)로 수문, 토양, 식생, 지형 학적 특징을 중요시하고 있어 $\mathrm{MA}(2005)$ 에서 제시한 생태계 서비스 분류체계와 연계가 가능하다. 습지가 제공하는 생태계 서비스의 주요 요소는 수문, 토양, 


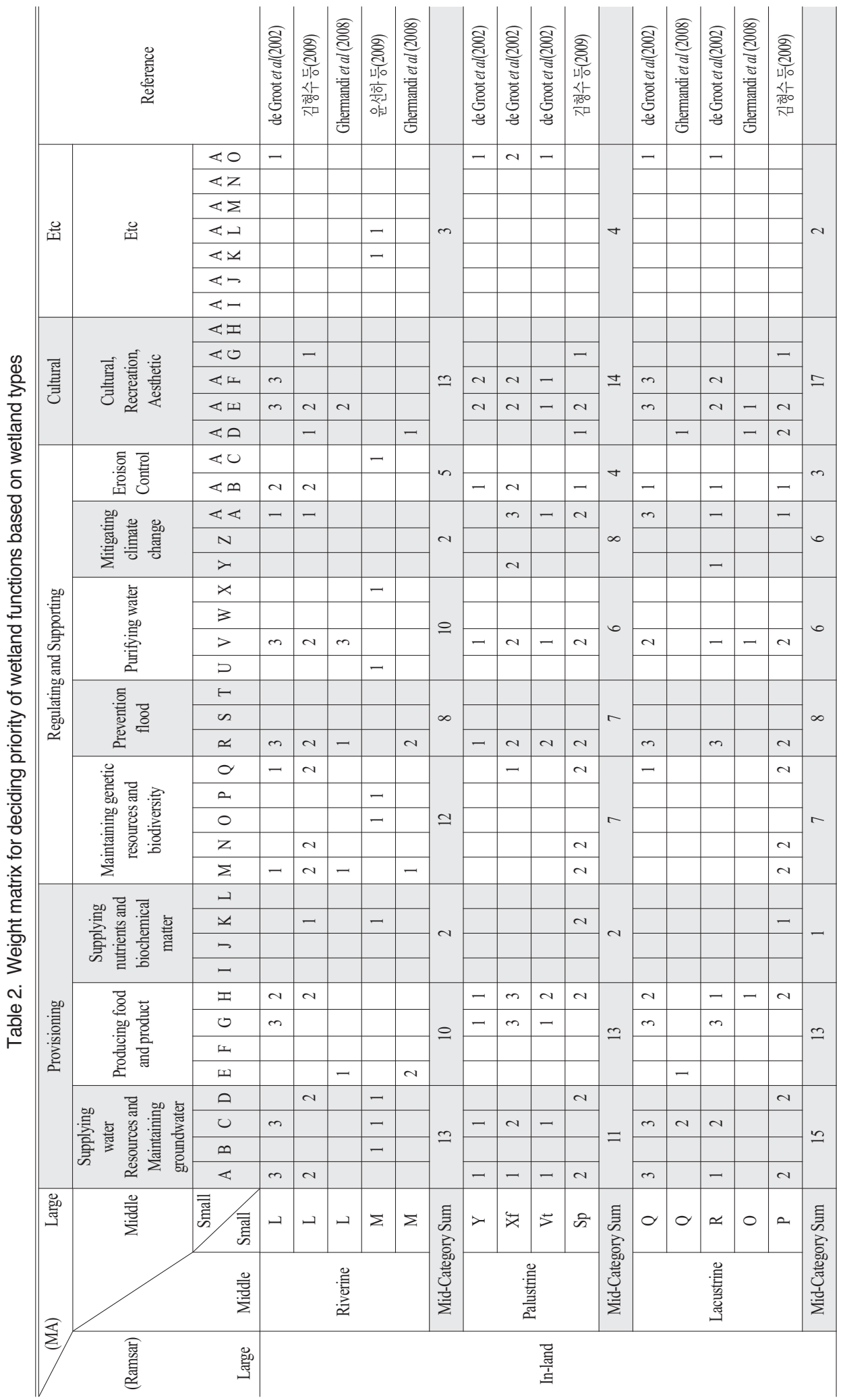




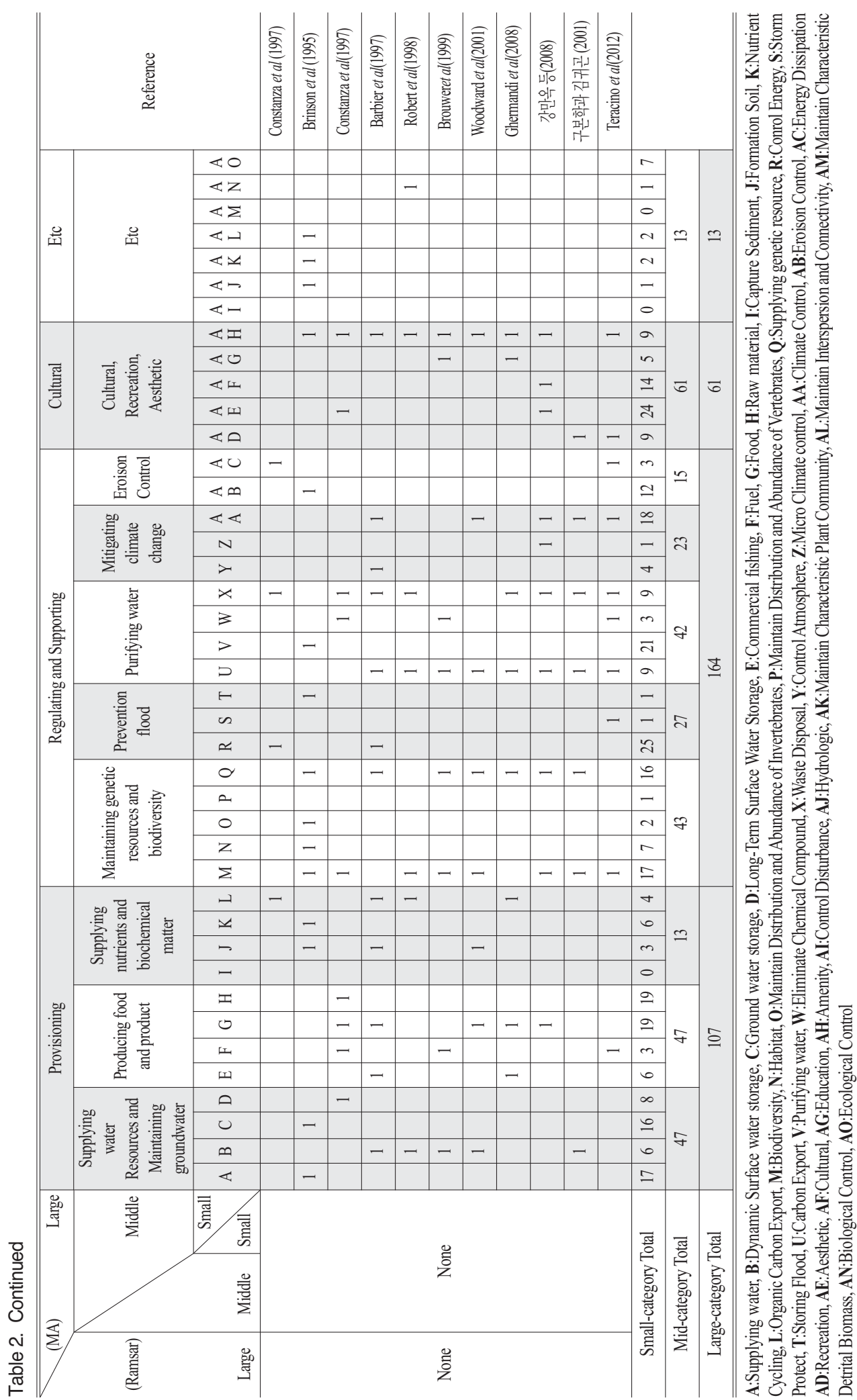


Table 3. Priority of wetland function based on type

\begin{tabular}{c|l|c}
\hline \hline Class & \multicolumn{1}{|c|}{ Priority } & \multicolumn{1}{|c}{ Note } \\
\hline Large & Regulating and Supporting $>$ Provisioning $>$ Cultural $>$ Etc. & MA (2005) Service Based \\
\hline Middle & $\begin{array}{l}\text { Cultural } \cdot \text { Recreational }>\text { Supply water and Ground water }>\text { Produce food and product }>\text { Maintain } \\
\text { Genetic resource and Biodiversity }>\text { Purifying water }>\text { Prevent Flood }>\text { Mitigating climate change } \\
>\text { Eroison control }>\text { Etc }>\text { Nutrient and Biochemical matter }\end{array}$ & \\
\hline Small & $\begin{array}{l}\text { Energy Dissipation }>\text { Purifying water }>\text { Aesthetic }>\text { Water Supply }>\text { Ground water discharge }> \\
\text { Raw material }>\text { Food }>\text { Eroison control }>\text { Recreation }>\text { Habitat }\end{array}$ & Top 10 item \\
\hline \hline
\end{tabular}

식생을 갖추는 분류체계로 우리나라 국가 습지 인벤 토리 구축(구본학 등, 2008)에서도 람사르 분류코드 확장방식(Ramsar Convention Secretariat, 2006) 을 기초 하여 유형구분을 하고 있어 향후 습지가 가 지고 있는 가치를 평가시 반영 할 수 있을 것으로 사 료된다.

\section{(2) 세분류 기능의 우선순위}

Table 3에서 세분류 기능에 대한 우선순위를 살펴 보면 홍수방지 및 침식방지에 해당하는 에너지 감쇄 기능이 가장 큰 것으로 나타났다. 에너지 감쇄기능은 흐르는 하천의 에너지를 효과적으로 감쇄시켜 하도 의 세굴과 제방의 침식을 방지하고 홍수량을 저감시 켜 하류 하도에 부담을 덜어주는 기능이다(오경두, 2009). 주로 수문과 관련된 기능에서 높은 우선순위 가 나타났지만 습지의 기능을 세분류로 나누어 평가 할 경우 뚜렷한 경향성이 나타나지 않기 때문에, 세 분류 수준의 우선순위 결과만으로는 우선순위 타당 성 판단에 한계가 있는 것으로 판단된다.

\section{(3) 중분류 기능의 우선순위}

Table 3 과같이 중분류 기준을 통해 평가한 기능의 우선순위는 수자원함양 및 지하수 유지기능, 문화 . 레크레이션 기능, 식량 및 제품생산 기능, 수질정화 기능 순으로 나타났다. 중분류 우선순위 평가 결과를 물리적 측면에서 보았을 때, 하천습지의 특성상 습지 가 갖고 있는 수질정화 기능 보다는 홍수 조절이나 지하수 보충 - 유지와 같은 기능이 우선 한다는 것을 의미한다. 또한, 습지의 기능 중 주목해야 할 또 다른 기능은 문화적 기능인데, 레크레이션과 심미적인 기 능에 대해 거의 모든 사례연구에서 높게 평가되고 있 었으며, 본 연구의 우선순위 결과에서도 2 순위로 높
게 나타났다. 중분류 기능 우선순위 결과는 습지의 주요한 기능에 대해서 전체적으로 고려한 것이기 때 문에, 세분류 기능의 결과보다 일관성 측면에서 더욱 의미를 지니는 것으로 판단된다. 그러나 본 연구는 기존 사례연구를 바탕으로 하였기 때문에 국내·외 습지에 대한 모든 유형과 기능을 반영하지 못한 한계 점을 갖고 있다. 향후 추가연구를 통해 더 많은 사례 가 포함된다면 더욱 정확한 우선순위 평가가 될 수 있을 것으로 사료된다.

\section{(4) 대분류 기능 우선순위}

Table 3에서 연구 사례 별 각 기능을 MA(2005)의 분류체계에 따라 대분류하여 우선순위를 선정한 결 과, 습지에서는 조절 및 지원에 대한 서비스가 가장 높게 평가되었다. 공급 서비스, 문화서비스 등의 중 요성이 차례로 선정되었다. 이는 습지의 에너지 감 쇄, 정수작용, 수원함양 등을 고려할 때 비교적 타당 한 우선순위라 판단된다.

\section{RAM결과와의 비교검증}

$\mathrm{RAM}$ 은 미국의 대표적인 습지의 일반적인 평가기 법으로서, 습지관리 전략 수립을 기초 평가 시 RAM 을 적용한다(구본학 - 김귀곤, 2001). RAM 평가는 습지의 기능을 8개로 나누고 각 기능을 2 9개의 평 가요소로 기준을 만들어 점수로 평가하고 높음, 보 통, 낮음 3 개의 단계로 등급화를 한다. RAM 평가에 서 정의하고 있는 습지의 기능은 서식처기능(식생다 양성 및 야생동식물서식처, 어류 및 양서파충류 서식 처), 수리수문적 기능(홍수저장 및 조절, 표면 유하저 감, 호안 및 제방 보호, 지하수 유지 및 보충), 수질정 화기능(수질보호 및 개선), 미적기능(미적-레크레이 션) 등 크게 4 가지 기능으로 묶어 볼 수 있다. 
Table 4. Result of RAM on riverine wetland (Reverine type from 전우송 등(2007))

\begin{tabular}{|c|c|c|c|c|c|c|c|}
\hline \multirow[b]{2}{*}{$\begin{array}{c}\text { Ramsar } \\
\text { code(type) }\end{array}$} & \multicolumn{5}{|c|}{ Assessment item } & \multicolumn{2}{|c|}{ Note } \\
\hline & $\begin{array}{l}\text { Maintaining } \\
\text { Vegetation } \\
\text { Diversity }\end{array}$ & $\begin{array}{c}\text { Flood Storage } \\
\text { and Control }\end{array}$ & $\begin{array}{l}\text { Protecting and } \\
\text { Improving the } \\
\text { Quality of water }\end{array}$ & $\begin{array}{l}\text { aesthetic, } \\
\text { recreation }\end{array}$ & $\begin{array}{l}\text { Maintaining } \\
\text { and supplying } \\
\text { Groundwater }\end{array}$ & Reference & Name \\
\hline $\begin{array}{c}\mathbf{M} \\
\text { (Riverine) }\end{array}$ & 2.50 & 2.33 & 1.88 & 2.67 & 2.00 & $\begin{array}{c}\text { 전우송 등 } \\
\text { (2007) }\end{array}$ & $\begin{array}{l}\text { Han-River } \\
\text { Duomo }\end{array}$ \\
\hline $\begin{array}{c}\text { M, L, Xf } \\
\text { (Riverine) }\end{array}$ & 2.66 & 2.00 & 1.83 & 2.66 & 2.00 & $\begin{array}{c}\text { 전우송 등 } \\
\text { (2007) }\end{array}$ & Imjing River \\
\hline $\begin{array}{c}\mathbf{M}, \mathbf{X f} \\
\text { (Riverine) }\end{array}$ & 2.50 & 2.25 & 1.88 & 2.50 & 2.50 & $\begin{array}{l}\text { 전우송 등 } \\
\text { (2007) }\end{array}$ & Sukgyuchun \\
\hline $\begin{array}{l}\text { M, Xf, Ss } \\
\text { (Riverine) }\end{array}$ & 2.40 & 2.25 & 2.00 & 2.50 & 1.75 & $\begin{array}{l}\text { 전우송 등 } \\
\text { (2007) }\end{array}$ & Hwapochun \\
\hline $\begin{array}{c}\text { M, Tp } \\
\text { (Riverine) }\end{array}$ & 2.89 & 2.50 & 2.25 & 2.50 & 2.00 & $\begin{array}{l}\text { 전우송 등 } \\
\text { (2007) }\end{array}$ & Geum river \\
\hline $\begin{array}{c}\text { M, L, Xf } \\
\text { (Riverine) }\end{array}$ & 2.20 & 2.50 & 1.88 & 2.33 & 2.50 & $\begin{array}{l}\text { 전우송 등 } \\
\text { (2007) }\end{array}$ & Mulgubie \\
\hline Avg & 2.5 & 2.34 & 1.9 & 2.4 & 2.2 & & \\
\hline
\end{tabular}

L: Permanent inland deltas, M: Permanent rivers/streams/creeks, Ss: Seasonal/intermittent saline/brackish/alkaline marshes/pools, Tp: Permanent freshwater marshes/pools, Xf: Freshwater, tree-dominated wetlands

Table 5. Comparison between the function of riverine wetlands and assessment element

\begin{tabular}{c|c}
\hline \hline Existing Research (Type of wetland-Table 2) & RAM Result (구본학 · 김귀곤, 2001) \\
\hline Cultural, Recreation, aesthetic & Aesthetic, Recreation \\
\hline Supplying water resource and Maintaining ground water & $\begin{array}{c}\text { Maintaining and supplying } \\
\text { ground water }\end{array}$ \\
\hline Maintaining genetic resources and biodiversity & Maintaining vegetation diversity \\
\hline Purifying water resource & Protecting the quality of water resource \\
\hline Preventing flood & $\begin{array}{c}\text { Storing and Controlling } \\
\text { flood }\end{array}$ \\
\hline \hline
\end{tabular}

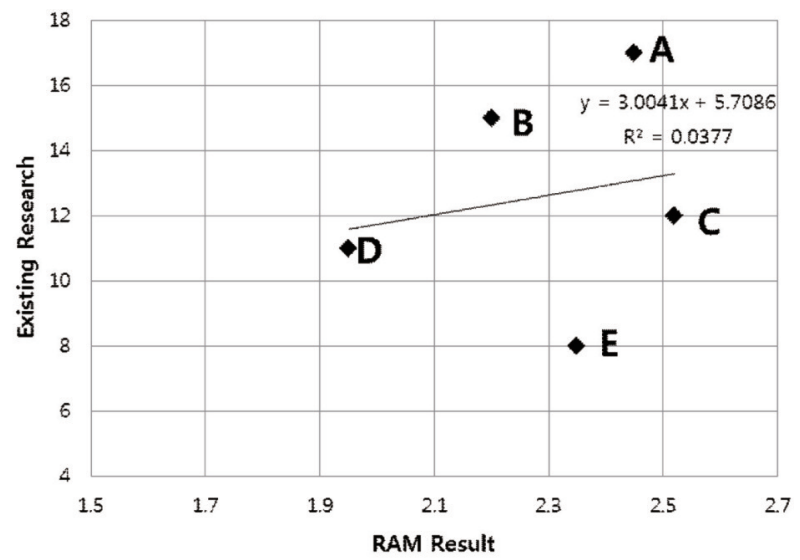

Legend based on collected existing research(Table 2)

A: Cultual, aesthetic and recreation

B: Water supply and maintaining ground water

C: Maintaining genetic resource and biodiversity

D: Purifying water quality

E: Preventing flood

Figure 2. Comparison between sum of weight and RAM result of riverine wetland

본 연구의 우선순위 결과를 람사르유형으로 재분 류한 결과 사례연구의 하천형의 결과와 전우송 등 (2007)이 진행한 RAM 평가 방법의 결과 중 ‘하천형
습지' 평가에 대한 기능이 가장 흡사하였다. 전우송 등(2007)의 연구에서는 일반적으로 하천형으로 구분 되는 습지가 모두 하천습지로 분류되어 있다. RAM 
의 하천습지 결과와 비교를 하였다. Table 2 의 사례 연구를 통한 가중치 합산 자료와 전우송 등(2007)이 정리한 Table 4 의 국내 습지의 RAM결과 중 하천습 지에 대한 5 개 기능평가의 평균값을 Table 5 와 같이 비교하였다.

그 결과, 본 연구의 우선순위 결과는 중분류 수준 에서 문화적 기능이 가장 높게 측정이 되었고 그 뒤 로 수자원 함양, 유전 다양성 기능이 그 뒤를 이었는 데, 국내에서 RAM으로 평가되었던 연구 결과와 비 교하였을 때, 문화 · 레크레이션(A), 수자원함양(B), 수질보호(D) 관련 기능은 하천습지에서 어느 정도 상 관성이 있다고 판단되었다. 그러나 종다양성 $(\mathrm{C})$, 홍 수방지(E) 관련 기능에서는 상관성을 확인할 수 없었 는데, 이는 사례의 다양성이 추가되거나 RAM결과의 검증에 의해 보완 · 수정이 가능할 것으로 판단된다. 보다 정량적인 비교를 위해, 국내외 연구사례 우선순 위 결과를 바탕으로 하천형 내륙습지의 RAM결과 산 점도(Scatter Plot)를 생성한 결과, 유형에 대한 기능 의 우선순위가 다소 뚜렷하게 나타나지는 않았지만 어느 정도 유의미한 영향관계가 있는 것으로 나타났 다(Figure 2). 본 연구에서는 이러한 방법을 통해 우 선순위에 결정 결과에 대하여 비교하였지만, 각 습지 에 대한 평가방법이 서로 차이가 있으며, 비교 대상 이 명확하게 일치하지 않는 경우가 많아 우선순위를 검증하는 것은 여전히 한계가 있는 것으로 사료된다.

\section{IV. 결 론}

자연자산이 가지는 공급, 조절, 문화기능을 평가 하기 위한 시도는 다양한 평가방법을 바탕으로 진행 되고 있다. 다양한 연구에서 생태계 서비스 가치는 자연자산 관리를 위한 의사결정 지원에 활용하기 위 한 것으로 평가 되고 있다. 그러나 습지가 제공하는 기능에 대한 가치를 정량적으로 추정하기 어려워 정 책결정자들이 활용할 수 있는 습지 가치가 평가된 정 보는 매우 제한적이다. 습지의 가치를 평가하는데 있 어 습지 기능을 분류하고 기능에 대한 중요도를 판단 하는 것이 필요하다. 또한, 국내 습지 기능에 대한 평 가 기준이 모호하고 습지마다 중요도에 따른 기준과
우선순위를 결정함에 한계가 있다. 본 연구에서는 이 를 개선하기 위하여, 기존의 연구에서 기술된 중요도 판단의 결과를 종합하여 기능의 우선순위를 부여하 였다. 본 연구의 우선순위 도출결과 세분류에서는 에 너지감쇄기능(홍수방지), 정수기능, 심미적기능, 수 원함유기능, 지하수저장기능 순으로 나타났지만 그 우선순위의 타당성을 파악하기 어려웠다. 중분류에 서는 수자원함양기능, 문화 - 레크레이션 기능, 식량 및 제품생산 기능, 수질정화 기능 순으로 나타났으 며, 그 우선순위가 비교적 타당한 것으로 파악되었 다. 대분류에서는 조절 및 지원, 공급, 문화 순으로 우선순위가 나타나 조절 및 지원기능이 우선적으로 중요한 것으로 나타났다. 검증 결과에서도 하천습지 의 경우 본 연구에서는 기능에 대한 우선순위가 미적 레크레이션 기능, 수자원함양기능, 유전자원 및 종 다양성 기능, 수질정화 기능, 홍수방지 기능 순으로 나타났으며, RAM 평가결과에서도 종 다양성 기능, 미적 레크레이션 기능, 홍수조절 기능, 지하수 유지 및 보충(수자원 함양)기능, 수질보호 기능 순으로 유 사하게 나타났다. 기존 연구 사례의 대상지는 다소 산 발적이어서 유형별 우선순위에 대한 검증이 어려웠 지만 본 연구는 습지의 기능을 군집화를 통해 재분류 하고 여러 연구사례를 통한 기능 우선순위를 결정하 여 습지를 평가하는 부문에서 기초를 제공하였다고 판단된다. 본 연구는 대표적인 습지보전가치판단기 준인 RAM을 이용하여 내륙습지의 생태계 서비스 우 선순위를 검증하였으며, 향후 이를 바탕으로 보전가 치를 도출하여 습지보전방안 수립의 기초자료로 이 용하고자 진행하였다. 그러나 본 연구의 우선순위 결 과가 실제 보전가치 판단에 활용되기 위해서는 습지 의 각 기능에 바탕을 둔 습지 기능 평가와함께 수문, 토양, 식생 및 지형조사를 바탕으로 생태계 서비스와 편익과의 관계를 분석할 필요가 있다고 판단된다.

\section{사 사}

본 연구는 2012년도 환경부 차세대 에코이노베이 션 기술 개발사업 지원으로 수행되었음(과제번호: 2012-00021-0002). 


\section{참고문헌}

강만옥 등, 2008 , 우리나라 주요 습지의 경제적 가

치 평가 연구, 한국환경정책 - 평가연구원 보고서.

강수진, 2004 , 습지기능을 고려한 한국 내륙습지의 간이 평가 기법 개발 및 적용, 석사학위논 문, 이화여자대학교.

구본학, 김귀곤, $2001, \mathrm{RAM}$ (일반기능평가기법)을 이용한 내륙 습지 기능 평가, 한국환경복원 녹화기술학회지 4(3), 38-48.

구본학 등, 2008 , 국가습지유형분류체계 연구, 환 경부 $\mathrm{UNDP} / \mathrm{GEF}$ 국가습지보전사업관리단 최종보고서.

김종호, 이경학, 박찬우, 서정원, 손영모, 김경하, 윤호중, 박찬열, 이승우, 오정수, 2006, 산 림의 공익기능 평가, 한국산림휴양학회지, 10(2), 7-15.

김형수, 김재근, 유병국, 2009, 4대강 생태습지조 성모델 및 평가기법개발 연구, 국토해양부 보고서.

신한규, 김덕길, 김재근, 김형수, 안재현, 유병국, 안경수, 박두호, 2009 , 댐습지의 기능 및 가 치평가 연구(1) $-\mathrm{HGM}$ 을 이용한 기능평가: 보령댐을 대상으로, 한국습지학회지, 11(3), 115-132.

오경두, 2009 , 녹색성장을 위한 습지의 재조명, 물 과 미래, 42(12), 10-30.

윤선하, 김덕길, 김형수, 2009 하천변 습지의 기능 평가 연구, 대한토목학회, 2009, 대한토목 학회 정기학술대회, 3431-3434.

이관규 등, 2010 , 국가습지의 유형별 · 등급별 분류 및 유형별 습지복원 매뉴얼 작성 연구, 환경 부 보고서.

이상영, 2007 , 제주초지의 사회, 문화적 기능 가치 평가 및 보전방안, 농촌계획, 13(4), 23-30. 전우송 등, 2007 , 제1차 국가습지 인벤토리 구축사 업, 환경부 $\mathrm{UNDP} / \mathrm{GEF}$ 국가습지보전사업 관리단 최종보고서.
환경부, 2011 , 제 3 차 전국내륙습지 조사지침 작성 연구.

Barbier, E. B., M. C. Acreman, and D. Knowler, 1997. Economic valuation of wetlands: A guide for policy makers and planners. Ramsar Convention Bureau, Gland, Switzerland.

Brinson, M. M., R. D. Rheinhardt, F. R. Hauer, L. C. Lee, W. L. Nutter, R. D. Smith, and Whigham, D., 1995, A Guide for Application of Hydrogeomorphic Assessment to Riverine Wetlands, US Army Corps of Engineers.

Brouwer, R., Langford, I. H., Bateman, I. J., and Turner, R. K, 1999, A meta-analysis of wetland contingent valuation studies, Regional Environmental Change, 1(1), 47-57.

Costanza, R. et al., 1997, The value of the world's ecosystem services and natural capital, Nature, 387(15), 253-260.

de Groot, R. S., Wilson, M. A., and Boumans, R. M., 2002, A typology for classification, description and valuation of ecosystem functions goods and services, Ecological Economics, 41(3), 393-408.

Ghermandi, A., Van den Bergh, J., Brander, L., De Groot, H., and Dias Nunes, P., 2008, The Economic Value of Wetland Conservation and Creation: A MetaAnalysis, NOTA DI LAVORO, 79, 2008.

Hammitt, J. K., Liu, J. T., and Liu, J. L., 2001, Contingent valuation of a Taiwanese wetland, Environment and Development Economics, 6(2), 259-268.

Millennium Ecosystem Assessment, 2005, Ecosystems and Human Well-being: A Framework for Assessment. Washington, DC: Island Press. 
Ramsar, 1971, A global action plan for the wise use and management of peatlandsRecommendation of the Ramsar Convention on wetlands, San Jose, Costa Rica, 10-18 May 1999.

Ramsar Convention Secretariat, 2006, The Ramsar Convention Manual: a guide to the Convention on Wetlands (Ramsar, Iran, 1971), 4th ed. Ramsar Convention Secretariat, Gland, Switzerland.

Robert, M., 1998, Wetlands Environmental Assessment Guideline, Minister of Public Works and Government Services Canada.

Sutula M. A., Stein, E. D., Collins, J. N., Fetscher, A. E., and Clark, R., 2006, A Practical Guide for the Development of a Wetland Assessment Method: the California Experience, Journal of the
American Water Resources Association, February.

Teracino, L., 2012, A world in our backyard, United States Environmental Protection Agency, Chapter 3 Wetland Functions.

Tilton, D. L., Karen, S., Brian, B., and Thomas, W., 2001, A Wetland Protection Plan for the Lower One Subwatershed of the Rouge River, Rouge River National Wet Weather Demonstration Project.

Whigham, D. F., 1999, Ecological issues related to wetland preservation, restoration, creation and assessment, The Science of the Total Environment, 240(1999), 31-40.

Woodward R. T., and Wui, Y., 2001, The economic value of wetland services: a meta-analysis, Ecological Economics, $37(2), 257-270$. 